\title{
Upconversion fluorescence resonance energy transfer-a novel approach for sensitive detection of fluoroquinolones in water samples
}

\author{
Zhen Zhang a,b , Meng Zhang a , Xiang-yang Wu ${ }^{a}$, Zhen Chang ${ }^{a}$, Yong-Ill Lee ${ }^{\mathrm{b}, *}$, Bui The Huy ${ }^{\mathrm{b}}$, \\ Kavitha Sakthivel ${ }^{\mathrm{b}}$, Jing-fu Liu ${ }^{\mathrm{c}}$, Gui-bin Jiang ${ }^{\mathrm{c}}$ \\ a School of the Environment, Jiangsu University, Zhenjiang 212013, China \\ b Department of Chemistry, Changwon National University, Changwon 641-773, Republic of Korea \\ c State Key Laboratory of Environmental Chemistry and Ecotoxicology, Research Center for Eco-Environmental Sciences, Chinese Academy of Science, P.O. Box 2871, Beijing 100085, China
}

\section{A R T I C L E I N F O}

\section{Article history:}

Received 26 August 2015

Accepted 27 August 2015

Available online 5 September 2015

\section{Keywords:}

Upconversion

Fluoroquinolone

Fluorescence resonance energy transfer

Nanoparticle

\begin{abstract}
A B S T R A C T
A novel homogeneous assay method was put forth for simultaneous sensing of fluoroquinolone derivatives (FQs) in water utilizing the upconversion fluorescence resonance energy transfer (FRET) process based on the competitive reaction between dissolved FQs and labeled AuNPs for FQs Mab connected UCPs. The prepared size-tunable $\beta-N a L u F 4: Y b, E r, G d$ upconversion phosphors (UCPs) were functionalized with carboxylic acid ( $\mathrm{COOH}-$ ) and monoclonal antibody (Mab, C2F3C2) to act as a donor. The gold nanoparticles (AuNPs) labeled with the corresponding antigen (ciprofloxacin-BSA) take the role of an acceptor. Under optimized conditions, the limit of detections (LODs) for three common FQs, enrofloxacin (ENR), ciprofloxaxin (CIP), and norfloxacin (NOR), were $0.19-0.32 \mathrm{ng} / \mathrm{mL}$ based on $3 \sigma$. The recoveries were found to be in the range of $73.5-114.5 \%$ (normalized value according to the cross-reactivity of Mab) for water samples (tap water, pond water and river water). The proposed approach possesses significant advantages as follows: (i) simple procedure (only one step) without washing and separation steps, and no sample pretreatment other than filtration; (ii) fast liquid-phase kinetics with shortened incubation time; and (iii) high tolerance to various interfering substances. All of which indicated its potentiality as an efficient biosensor towards the monitoring of FQs in aquatic environments.
\end{abstract}

() 2015 Elsevier B.V. All rights reserved.

\section{Introduction}

Fluoroquinolones (FQs) belong to the class of synthetic antibiotics with a broad spectrum of activity against both gram-positive and gram-negative bacteria. Its potential has been appropriately centralized for the treatment of respiratory diseases and bacterial infections both in human and farm animals [1-3]. However, prior reports show the extensive usage of this antibiotic for pharmaceutical purposes has resulted in a widespread contamination of environmental water [4-9]. In view that the chemicals could cause adverse effect on the aquatic vertebrates and organisms, and their increased level of bacterial resistance, more and more concerns arose on the potential risk on human health and aquatic ecosystem [10-14]. So, some effective approaches were put forward to monitor FQs in environmental water.

Currently several analytical methods were conventionally used for the detection of FQs in water samples. Among them, the chromatographic method utilizing solid-phase extraction (SPE) as a pre-concentration step is widely adopted $[2,15]$. However, the drawbacks of being laborious, time-consuming and solvent intensive limited their application. As an alternative, high-throughput

\footnotetext{
* Corresponding author. Tel.: + 8255213 3436; fax: + 82552133439.

E-mail address: yilee@changwon.ac.kr (Y.-I. Lee).
}

immunoassay is a good choice for analysis of FQs from water samples, depending on their outstanding properties, the assays could screen containments from large amounts of samples in a short period of time [16-20]. But the methods cannot be done with an automated instrument, and cannot carry out on-site analysis for the organic pollutants because of relatively sophisticated procedures.

To reduce the cumbersome immunoassay steps and obtain quick information from solution samples, fluorescence resonance energy transfer (FRET) was introduced, in FRET process, the energy is transferred from the donor to the acceptor through non-radiative dipole-dipole interactions [21-27]. In fact, before an effective FRET occurs, two conditions must be met as: (i) the fluorescent donor molecule and an acceptor molecule that are brought in a close proximity to each other; (ii) a strong overlap between the emission spectrum of the donor and the absorption spectrum of the acceptor [28-30]. To obtain better sensitivity using FRET assay, the long-lived emission from Lanthanide-based upconversion nanoparticles (UCPs) was selected as a candidate of energy donors, which was because it could extend the observed lifetime of the sensitized acceptor emission, allowing energy-transfer signals to be measured in a time-resolved manner without direct acceptor emission, autofluorescence and scattered excitation [31,32]. In addition, UCPs under IR excitation possess many fascinating properties, such as low toxicity, nearly-zero background autofluorescence, high 
photoluminescence intensity and photostability [33-35]. All of which indicated that UCP has unique advantages as a potential energy donor.

However, hydrophobic UCPs cannot be directly labeled by antibodies and used in the biology detection because of low solubility in water and unfavorable surface properties, it has to be converted into biocompatible one using appropriate functional groups $\left(-\mathrm{COOH},-\mathrm{NH}_{2},-\mathrm{SH}\right)$ through exchange ligand process or UCPs-SiO 2 core-shell structure [24,36-38]. At present, the method of encapsulation with $\mathrm{SiO}_{2}$ was widely used as a surface functionalization of hydrophobic UCPs, but this procedure was suffered from high cost, complicated procedures and difficulty in controlling the thickness and uniformity of the $\mathrm{SiO}_{2}$ layer. Moreover, a thick layer of $\mathrm{SiO}_{2}$ shell could deteriorate the analytical performance of FRET assay because of the increase in distance between the donor and the acceptor molecule. In order to ensure a close proximity between UCPs and fluorescent acceptor for efficient energy transfer, a direct surface modification that converts hydrophobic nanoparticles (NPs) into water-soluble ones without any coating layers was implemented [34].

In the present work, a highly monodisperse and uniform UCPs were synthesized, and the surface was modified into biocompatible by adopting the poly(acrylic acid) (PAA)-based ligand exchange strategies $[36,39]$. The UCPs were made as an energy donor after their surface functionalization with a group-specific Mab against FQs. At the same time, due to excellent absorption properties in the visible region [40], the AuNPs conjugated with antigens (ciprofloxacin-BSA) were chosen as acceptor molecule for the upconversion FRET measurements. A homogeneous upconversion FRET assay was developed for the simultaneous detection of FQs series in aqueous samples. The established method was evaluated with several factors that potentially influence its performance, and the accuracy of the assay also was investigated by spiked FQs in various water samples.

\section{Experiments}

\subsection{Chemicals}

$\mathrm{Lu}_{2} \mathrm{O}_{3}$ (99.99\%), $\mathrm{Yb}_{2} \mathrm{O}_{3}$ (99.99\%), $\mathrm{Er}_{2} \mathrm{O}_{3}$ (99.99\%) and $\mathrm{Gd}_{2} \mathrm{O}_{3}$ (99.99\%) were obtained from Minmetals Rare Earth Co. Ltd. (Ganzhou, China). Oleic acid (OA, 90\%) and poly(acrylic acid) (PAA, $\mathrm{M}_{\mathrm{w}}=1800$ ) were purchased from Sigma-Aldrich (St. Louis, MO, USA). 1-Octadecene (ODE, 90\%) and diethylene glycol (DEG, 90\%) were supplied by Alafa Aesar (Ward Hill, MA, USA). N-hydroxysuccinimide (NHS, 98\%), 2-(-N-morpholino) ethanesulfonic acid (MES, 99\%), ethyl-3-(3-dimethylaminopropyl) carbodiimide (EDC, 99.9\%), 4-(2-hydroxyethyl) piperazine-1-ethanesulfonic acid (HEPES, 99\%) and tris (hydroxymethyl) methanamine (Tris, 99.9\%) were obtained from Aladdin Chemical Co., Ltd. (Shanghai. China). Enrofloxacin (ENR, 99.9\%), ciprofloxacin (CIP) hydrochloride (99.9\%) and enoxacin (ENO, 99.6\%) were purchased from the China Institute of Veterinary Drug Control (Beijing, China). Bovine serum albumin (BSA) and chlorauric acid $\left(\mathrm{HAuCl}_{4}\right)$ were supplied by Sigma Chemical Co. All other chemicals were obtained from Nanjing Chemicals Co. Ltd (Nanjing, China). The Mab against 13 FQs was produced previously and shown in Table S1 (ESI - electronic supplementary information) [41].

\subsection{Solutions}

Buffers used in this study were as follows: MES buffer (10 mM, pH 5.5), HEPES buffer (10 mM, pH 7.2) and Tris- $\mathrm{HCl}$ buffer $(0.05 \mathrm{~mol} / \mathrm{L}, \mathrm{pH} 8.0)$ containing $0.9 \% \mathrm{NaCl}$. The rare earth chloride $\left(\mathrm{RECl}_{3}\right)$ was obtained as follows: $\mathrm{Lu}_{2} \mathrm{O}_{3}(1353.2 \mathrm{mg})$, $\mathrm{Yb}_{2} \mathrm{O}_{3}(354.7 \mathrm{mg}), \mathrm{Er}_{2} \mathrm{O}_{3}(354.7 \mathrm{mg})$ and $\mathrm{Gd}_{2} \mathrm{O}_{3}(38.3 \mathrm{mg}$ ) were added to $30 \mathrm{~mL}$ of hydrochloric acid (36.5\% hydrochloric acid/ water $=1: 2, \mathrm{v} / \mathrm{v}$ ) and concentrated to nearly dryness under
$70{ }^{\circ} \mathrm{C}$. Then, the mixture was dissolved in $50 \mathrm{~mL}$ of methanol and utilized for UCP synthesis.

\subsection{Instrumentations}

Fluorescence spectra of UCPs were recorded using a Lumina Fluorescence Spectrometer (Thermo Fisher Scientific) and modified with an external $980 \mathrm{~nm}$ laser (Beijing Hi-Tech Optoelectronic Co., China). The morphology of the synthesized UCPs was studied using a transmission electron microscope (TEM, H-800, Hitachi Ltd, Japan). X-ray powder diffraction patterns were obtained at a D8 advance X-ray diffractometer (Bruker Instruments Inc., Billerica, MA). The Fourier transform infrared spectroscopy (FT-IR) was performed on a Perkin-Elmer GX2000.

\subsection{Synthesis of the $\beta-N a L u F 4: Y b, E r, G d$ NPS}

Oil-dispersible $\beta$-NaLu $\mathrm{N}_{0.68} \mathrm{~F}_{4}: \mathrm{Yb}_{0.18}, \mathrm{Er}_{0.02}, \mathrm{Gd}_{0.12}$ UCPs have been successfully synthesized according to the earlier reported procedures with slight modifications [39,42-44]. Typically, (i) $\mathrm{Lu}_{2} \mathrm{O}_{3}(3.4 \mathrm{mmol})$, $\mathrm{Gd}_{2} \mathrm{O}_{3}(0.6 \mathrm{mmol}), \mathrm{Yb}_{2} \mathrm{O}_{3}(0.9 \mathrm{mmol})$, and $\mathrm{Er}_{2} \mathrm{O}_{3}(0.1 \mathrm{mmol})$ were added to $30 \mathrm{~mL}$ of hydrochloric acid solution (20:10; $\mathrm{v} / \mathrm{v}$ of $\mathrm{H}_{2} \mathrm{O} /$ concentrated $\mathrm{HCl}$ ). The mixture was heated at $70{ }^{\circ} \mathrm{C}$ for $1 \mathrm{~h}$ under reflux condenser. Then the mixture was evaporated to dryness using a vacuum evaporator. The obtained powder was dissolved in $50 \mathrm{~mL}$ of methanol, as a $\mathrm{RECl}_{3}$ precursor. (ii) $5 \mathrm{~mL}$ of $\mathrm{RECl}_{3}$ precursor, $\mathrm{OA}(8 \mathrm{~mL})$ and ODE $(18 \mathrm{~mL})$ were added to a three-necked flask that is fitted with a condenser, and heated to $160{ }^{\circ} \mathrm{C}$ under vigorous stirring (500 rpm) for $30 \mathrm{~min}$. The solution obtained was then cooled to room temperature (RT) and the solution turned transparent yellow. To this mixture was added $10 \mathrm{~mL}$ of methanolic solution containing $\mathrm{NH}_{4} \mathrm{~F}(4 \mathrm{mmol})$ and $\mathrm{NaOH}(2.5 \mathrm{mmol})$ and the entire mixture was stirred at room temperature for $90 \mathrm{~min}$, followed by heating at $300{ }^{\circ} \mathrm{C}$ under nitrogen atmosphere for $90 \mathrm{~min}$. The solution was brought down to RT. The final product was collected by centrifuging and subsequent washing with ethanol. The collected powder was dried at $60^{\circ} \mathrm{C}$ for $12 \mathrm{~h}$ under vacuum atmosphere.

\subsection{Conversion of hydrophobic UCPs into water-soluble ones}

The method was mainly based on the previously reported works [39, 42]. Typically, a mixture of PAA (0.5 g) and DEG (10 mL) was heated at $110{ }^{\circ} \mathrm{C}$ under vigorous stirring ( $500 \mathrm{rpm}$ ) for $10 \mathrm{~min}$. To the heated mixture, was added $5 \mathrm{~mL}$ toluene solution containing $30 \mathrm{mg} \mathrm{UCP}$ and stirred at $1800 \mathrm{rpm}$ in order to speed up the evaporation of toluene. When the temperature had reached $230{ }^{\circ} \mathrm{C}$, the exchange ligand process occurred violently, and so the stirring speed was reduced to $1000 \mathrm{rpm}$ in order to prevent the expulsion of the un-exchanged particles. This step was maintained for an hour and carried out in an inert atmosphere. The mixture was further cooled to RT followed by addition of dilute hydrochloric acid ( $\mathrm{pH} 4-5)$. The final product PAA-UCPs were collected by centrifugation process at $12,000 \mathrm{rpm}$ for $15 \mathrm{~min}$ and washed thrice with water/ethanol mixture $(1: 1, \mathrm{v} / \mathrm{v})$.

\subsection{Preparation of Mab-conjugated $\beta$-NaLuF4:Yb, Er, Gd UCPs}

Primarily, $5 \mathrm{mg}$ of PAA-UCPs was dissolved in $2 \mathrm{~mL}$ of MES buffer (0.195 g MES was dissolved in $100 \mathrm{~mL}$ ultrapure water and the $\mathrm{pH}$ was adjusted to 5.5 using $\mathrm{NaOH}$ ). The solution was filtered through a $0.22 \mu \mathrm{m}$ micropore membranes, sterilized and preserved at $4{ }^{\circ} \mathrm{C}$. It was then incubated in a shaker $\left(30^{\circ} \mathrm{C}, 160 \mathrm{rpm}\right)$ for $2 \mathrm{~h}$ after the addition of $4 \mathrm{mM}$ EDC and $10 \mathrm{mM}$ NHS. On centrifugation the precipitate was obtained which was then washed thrice with distilled water. The obtained precipitate and $0.5 \mathrm{mg}$ FQs-antibody were added to $2 \mathrm{~mL}$ of HEPES buffer $(0.238 \mathrm{~g}$ HEPES was dissolved in $100 \mathrm{~mL}$ ultrapure water, and $\mathrm{pH}$ adjusted to 7.2 using $\mathrm{NaOH}$ ), followed by subsequent shaking for about $2 \mathrm{~h}$ $\left(30^{\circ} \mathrm{C}, 160 \mathrm{rpm}\right)$. Any excess NHS was deactivated by the addition of 
$15 \mathrm{mg}$ bovine serum albumin (BSA). The entire content was centrifuged to obtain the final precipitate of Ab-UCNP. The precipitate was washed thrice with distilled water and dispersed in 1 mL HEPES buffer for further usage [39].

\subsection{Synthesis of Au NPs and preparation of antigen (CIP-BSA)-conjugated AuNPs}

AuNPs were synthesized and conjugated with antigen following prior reports $[29,45,46]$. Briefly, $1 \mathrm{~mL}$ of $\mathrm{HAuCl}_{4}(1 \%)$ was dissolved in $50 \mathrm{~mL}$ deionized water and heated to boiling. To it was added $1 \mathrm{~mL}$ of $2 \%$ sodium citrate solution and maintained at the same temperature for 15 min along with stirring. On cooling the mixture (final product) to RT, $50 \mathrm{~mL}$ of distilled water was added for further dilution. Subsequently, $0.5 \mathrm{~mL}$ of $8 \mathrm{mg} \mathrm{mL}^{-1}$ antigen was added into $800 \mathrm{~mL}$ Au NP solution (the $\mathrm{pH}$ was adjusted to 8.0 using borate buffer) under magnetic stirring in an ice bath for $1 \mathrm{~h}$. To the mixture was added $0.1 \mathrm{~mL}$ of $10 \%$ BSA solution under stirring for another $1 \mathrm{~h}$. The solution was then centrifuged at $6000 \mathrm{rpm}$ for $15 \mathrm{~min}$ at $4{ }^{\circ} \mathrm{C}$, and resultant sediment was washed with borate buffer solution for several times. After this step, the antigen (CIP-BSA)-conjugated AuNPs were stored in Tris- $\mathrm{HCl}$ buffer for further use.

Both Mab labeled UCPs and antigen conjugated AuNPs were stable for more 6 months and played a role as two components of FRET assay.

\subsection{FRET assay}

A simple approach was adopted and is detailed as follows. Typically, Mab labeled UCPs (prepared in the assay buffer) $\left(100 \mu \mathrm{L}, 12.5 \mu \mathrm{g} \mathrm{mL}{ }^{-1}\right)$, $72 \mu \mathrm{L}$ standard solutions or water samples and $28 \mu \mathrm{L}\left(0.125 \mu \mathrm{g} \mathrm{mL}{ }^{-1}\right)$ antigen conjugated AuNPs (dissolved in Tris- $\mathrm{HCl}$ buffer) were pipetted out into a series of fluorescence cuvettes. It was incubated for $1 \mathrm{~h}$ at room temperature with slow shaking. The experiments were repeated for 5 times. Analyses were carried out in triplicates and a sigmoidal standard curve was fitted to the mean values using Origin7.5 (Microcal, Studio City, CA).

\subsection{Tolerance evaluation and accuracy verification}

Interferences may arise due to matrix effects and variations in assay conditions and thus, cascading to unspecific reactions. Hence, the current method was evaluated for possible application using the water samples containing a series of heavy metals $\left(\mathrm{Cu}^{2+}, \mathrm{Hg}^{2+}, \mathrm{Pb}^{2+}, \mathrm{Cr}^{2+}\right)$, common ions $\left(\mathrm{Ca}^{2+}, \mathrm{Mg}^{2+}, \mathrm{K}^{+}\right.$and $\left.\mathrm{Na}^{+}\right)$at varying $\mathrm{pH}$ values. The accuracy of the method was evaluated using recoveries obtained from water samples (tap water, pond water and river water) spiked with typical FQs (NOR, ENR, and CIP). Tap water was collected from a lab in the school of environmental science, Jiangsu University. Pond water and river water samples were obtained from Neijiang River and adjacent rural areas. All the samples were filtered to remove particles larger than $0.22 \mu \mathrm{m}$ so that no FQs were present in the samples prior to FRET analysis.

\section{Results and discussion}

\subsection{Characterization of the donor}

In the present work, $\mathrm{NaLuF}_{4}$ was chosen as the host material, $\mathrm{Yb}^{3+}$ as the sensitizer and $\mathrm{Er}^{3+}$ as the activator. It is well known that $\mathrm{NaLuF}_{4}$ exists in two phases namely the hexagonal and cubic. The fluorescent intensity of hexagonal phase of $\mathrm{NaLuF}_{4}$ is higher than that of the cubic phase. The hexagonal phase $\mathrm{NaLuF}_{4}$ is often synthesized in organic solvents under high temperature or by using suitable dopants. $\mathrm{Gd}^{3+}$ was added to the system in order to increase the upconversion luminescence and for the reduction of particle size $[36,42,44,47]$. The shapes of the particles are highly influenced by the crystallographic phase of the initial seeds that have been formed during the nucleation process. The formation of a stable phase is highly dependent on the environmental factors, and especially on temperature. The reaction temperature dependence on size and fluorescent intensity of $\mathrm{NaLuF}_{4}$ are shown in Fig. S1 (ESI - electronic supplementary information). The small size and high fluorescent intensity of $\mathrm{NaLuF}_{4}$ UCPs were obtained using $18 \% \mathrm{~mol}$ of $\mathrm{Gd}^{3+}$ at $300{ }^{\circ} \mathrm{C}$. This temperature was chosen as an optimal reaction temperature.

The phase transition of NPs was also controlled by reaction time and hence, it was considered as an important factor in the synthesis of UCPs.
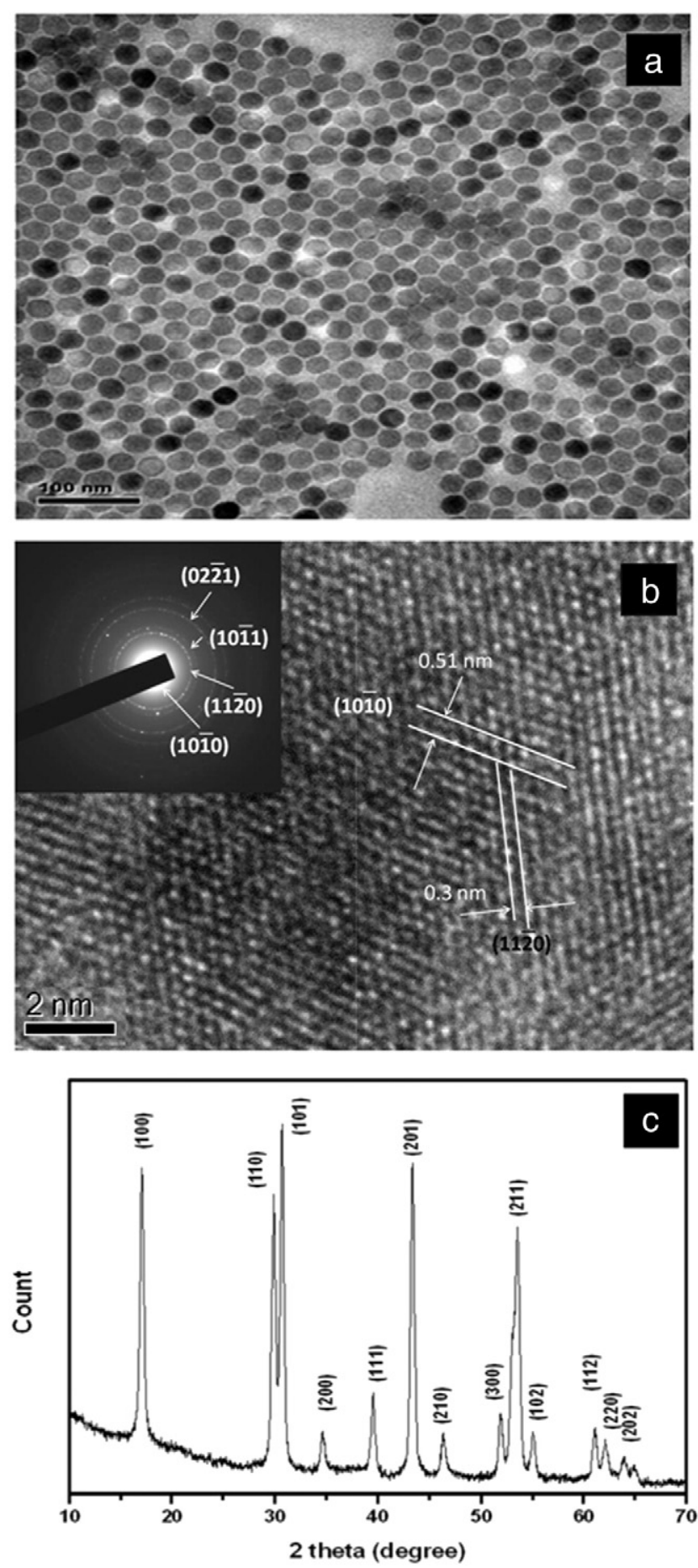

Fig. 1. Morphological studies of $\beta-\mathrm{NaLuF}_{4}: \mathrm{Yb}, \mathrm{Er}$, Gd NPs by using (a) FE-TEM, (b) high resolution-TEM, and (c) XRD spectrum. The inset in panel b shows the SAED pattern of the UCPs. 
The cubic phase does not seem to represent the state of equilibrium when the physical dimension of the initial particle increases to critical size of the phase transition. The reaction time is prolonged to cause a rapid dissolution of cubic phase seeds followed by the release of monomers, and thus resulting in a sudden nucleation of hexagonal phase seeds $[48,49]$. Both the cubic phase and hexagonal phase existed when the reaction was performed for duration of $30 \mathrm{~min}$ at $300{ }^{\circ} \mathrm{C}$. The phase transition from cubic phase to hexagonal phase started only after 60 min of the reaction at $300{ }^{\circ} \mathrm{C}$. This phase transition was confirmed by XRD analysis, as shown in Fig. S2 (ESI). When the reaction
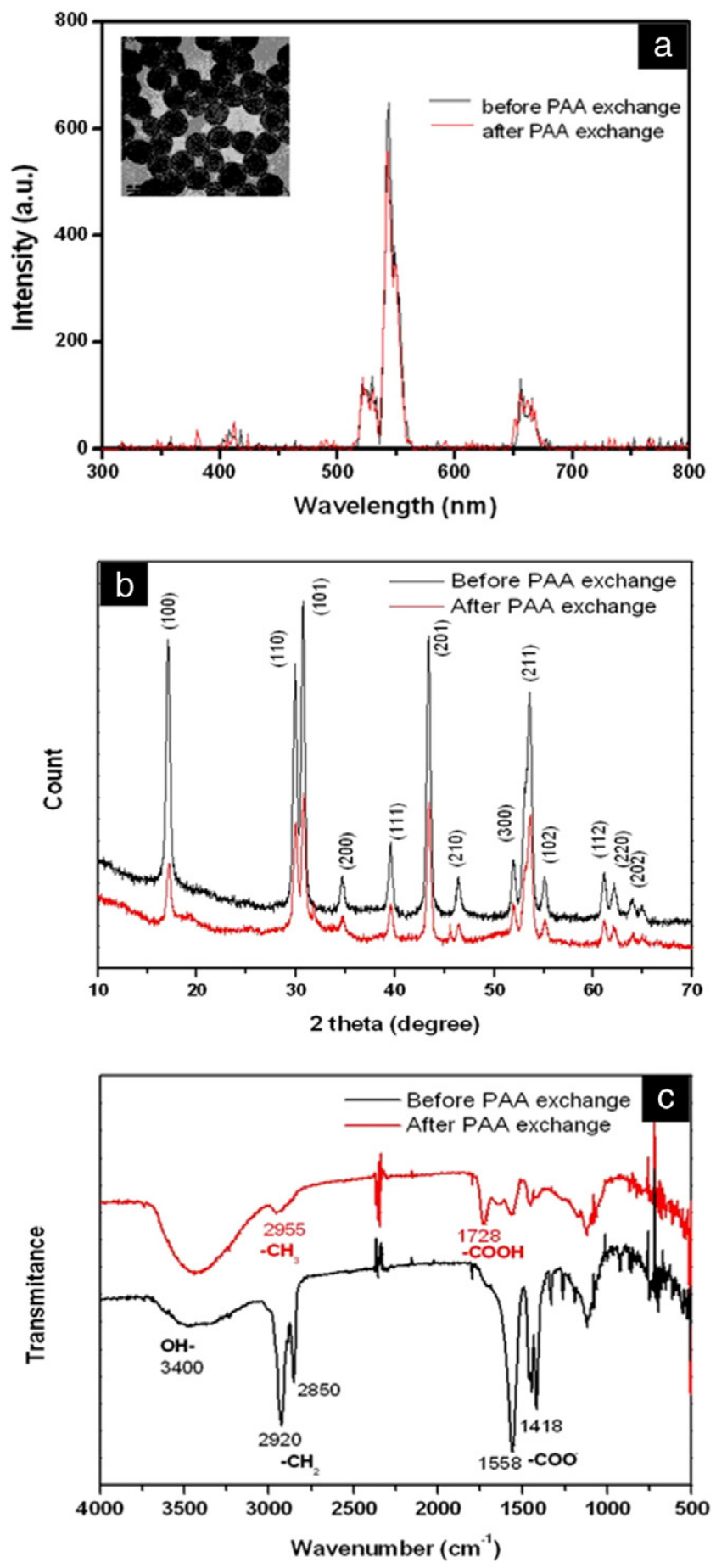

Fig. 2. (a) The comparison of fluorescence spectra between OA-capped hydrophobic UCPs and PAA exchanged-UCPs at an excitation wavelength of $980 \mathrm{~nm}$. Inset: the FE-TEM image of modified UCPs with PAA; (b) XRD pattern of UCPs before and after PAA exchange; (c) FT-IR spectra of the UCPs before and after PAA exchange. was carried out for $90 \mathrm{~min}$, the size of the obtained nanoparticles was found to be $\sim 25 \mathrm{~nm}$ and the shape was near hexagonal. Further prolongation of reaction time led to an increase in the crystal size $(\sim 160 \mathrm{~nm}$ after $10 \mathrm{~h}$ ) and therefore, resulted in a hexagonal shape, and is shown in the TEM images (Fig. S3 (ESI)).

Under the optimized conditions (reaction temperature, $300{ }^{\circ} \mathrm{C}$; reaction time, $90 \mathrm{~min}$ ), $\beta-\mathrm{NaLuF}_{4}$ : $\mathrm{Yb}, \mathrm{Er}, \mathrm{Gd}$ UCPs have a well dispersed, uniform, and a narrow size distribution with an average diameter of $\sim 25 \mathrm{~nm}$, as shown in Fig. 1a. With the high resolution transmission electron microscopy image (Fig. 1b), the interplanar distances are found to be $\sim 0.51$ and $0.3 \mathrm{~nm}$, which correspond to the d-spacing value of $(10 \overline{1} 0)$ and $(11 \overline{2} 0)$ planes of $\beta-\mathrm{NaLuF}_{4}: \mathrm{Yb}, \mathrm{Er}, \mathrm{Gd}$. The inset of Fig. $1 \mathrm{~b}$ shows the selected area electron diffraction (SAED) pattern of the UCP sample. Further confirmation of the above results was carried out using the powder X-ray diffraction (XRD) analysis (Fig. 1c). All the diffraction peaks could be indexed to the hexagonal phase (JCPDS No. 27-0726). The dominant hexagonal phase suggested that $\mathrm{Gd}^{3+}$ helps for the phase transition from cubic to hexagonal. The ionic radius of $\mathrm{Gd}^{3+}$ ion is larger than that of the $\mathrm{Lu}^{3+}$ ion in $\mathrm{NaLuF}_{4}$. Therefore, $\mathrm{NaLuF}_{4}$ codoped with a high concentration of $\mathrm{Gd}^{3+}$ tends to promote the phase transition from cubic phase to hexagonal phase because of the larger ionic radius of the doped ions that exhibit a high tendency towards the electron cloud distortion and thus, leading to an increased dipole polarizability [50].

The OA-capped hydrophobic UCPs were functionalized using PAA-based ligand exchange strategy instead of the conventional $\mathrm{SiO}_{2}$ encapsulation of hydrophobic nanocrystals [39,51]. The role of PAA was to replace monodentate OA shell on UCP surfaces by its multidentate binding sites. Fig. 2a confirmed the well dispersal of the surface modified UCPs in water and this may be ascribed to the presence of $-\mathrm{COOH}$ group on the surface. No obvious variation in fluorescence emission peaks and crystal structure was observed after the PAA exchange except for a slight decrease in emission intensity (Fig. 2a and b). This can probably be attributed to the quenching of water molecules after the introduction of the carboxyl groups [52]. Fourier transform infrared (FT-IR) spectroscopy was performed to verify the functional groups present on the surface of the NPs after the ligand exchange. As shown in Fig. 2c, the oleic acid exhibited a broadband around $3400 \mathrm{~cm}^{-1}$, corresponding to stretching vibration of a hydroxyl group. The peaks at approximately 2920 and $2850 \mathrm{~cm}^{-1}$ can be assigned to the asymmetric and symmetric stretching vibration of methylene $\left(-\mathrm{CH}_{2}\right)$ in the long alkyl chain. Two strong bonds were observed at 1418 and $1558 \mathrm{~cm}^{-1}$, respectively and it can be ascribed to the asymmetric and symmetric vibration modes of the $-\mathrm{COO}^{-}$group of the bound oleate ligand through the bidentate bonds [51,53,54]. After surface modification using PAA exchange, a strong bond was observed at $1728 \mathrm{~cm}^{-1}$. This peak is assigned to the $\mathrm{C}=0$ stretching vibration of the $-\mathrm{COOH}$ groups of the PAA. The shoulder observed at $2955 \mathrm{~cm}^{-1}$ associated with the asymmetrical stretching mode of $-\mathrm{CH}_{3}$ groups became inconspicuous after ligand exchange [42,51, $55,56]$. Based on FT-IR spectra and the good dispersal of UCPs in water after PAA exchange, they can be considered as the direct evidences for the exchange ligand process. After functionalization of the UCP surface with - $\mathrm{COOH}$ group, it was labeled with the FQs Mabs using cross-linkers (EDC), which activated the carboxy groups, and thus amide bonds were formed with the antibodies.

\subsection{FRET assay}

On excitation at $980 \mathrm{~nm}$, the UCPs showed a strong fluorescence (FL) emission at $543 \mathrm{~nm}$. This emission band was overlap with absorption band of the AuNPs (average diameter of $13 \mathrm{~mm}$ - Fig. S4 (ESI)), thus UCPs and AuNPs can function as a FRET donor and acceptor in the FRET pair, respectively (Fig. 3) [40,57]. 


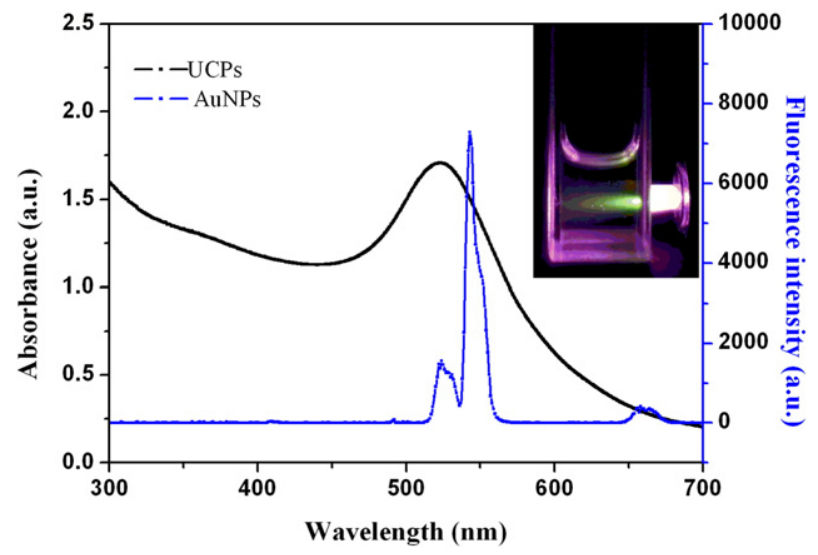

Fig. 3. Fluorescence spectra of UCPs under an excitation of $980 \mathrm{~nm}$; UV-Vis absorption spectrum of antigen-conjugated AuNPs. Inset: image of UCPS in water under $980 \mathrm{~nm}$ excitation.

Based on the above-mentioned donor and acceptor, a single-step homogeneous method had been developed and elaborated in Scheme 1. To better explain the principle of the method, it was divided into two major parts: firstly, the dissolved FQs and antigen conjugated AuNPs were competitively bound with the Mab labeled UCPs (the categories of FQs were determined by the cross-reactivities of the Mab, as seen in Table S1 (ESI)). The specific recognition between antibody and antigen makes both the NPs to attain a suitable spacing for the occurrence of FRET. Next, under an excitation of $980 \mathrm{~nm}$, the emitted green light of the UCPs was quenched quickly by the acceptor. As shown in Fig. 4a, the green fluorescence intensity is decreased gradually with increasing amount of antigen labeled AuNPs.

To obtain better performance, the quantity of labeled UCPs and AuNPs (connected with NOR-OVA) to be added in the assay was optimized using sensitivity as the key criterion, where three typical FQs (ENR, CIP and NOR) were selected for evaluation of the analytical performance of FRET assay. The standard calibration curves were constructed using various concentrations of FQs under the optimized conditions (donor; $100 \mu \mathrm{L} 12.5 \mu \mathrm{g} / \mathrm{mL}$, acceptor; $28 \mu \mathrm{L} 0.125 \mu \mathrm{g} / \mathrm{mL}$ ). Fig. 4b illustrates the constructed calibration curve for ENR as an example. The LODs for NOR, ENR and CIP were calculated as $0.32 \mathrm{ng} / \mathrm{mL}, 0.20$ $\mathrm{ng} / \mathrm{mL}$, and $0.19 \mathrm{ng} / \mathrm{mL}$, respectively, based on the mean of zero calibrators $(3 \sigma)$.

Without an expensive or sophisticated instrumentations, extensive sample preparation, and more skilled person required, the LOD values
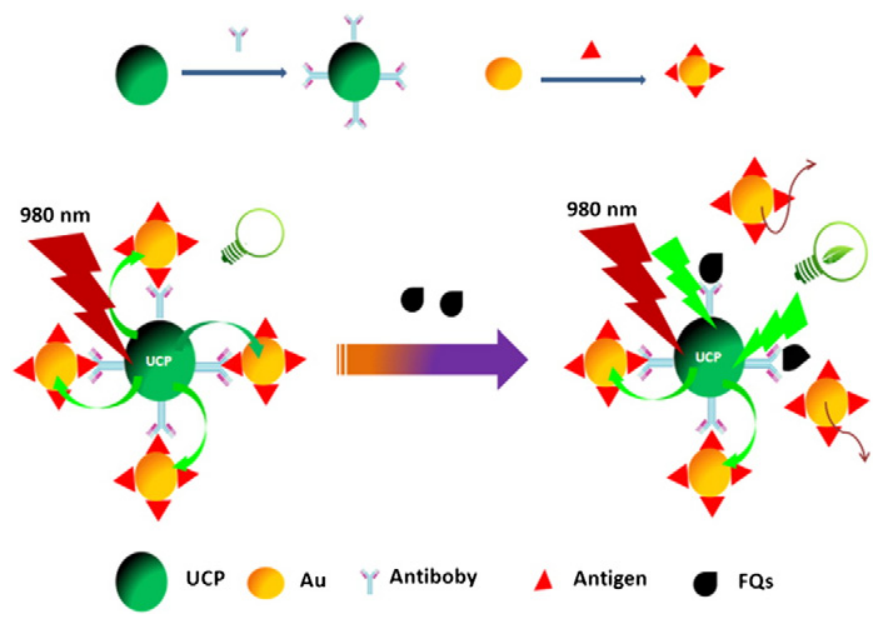

Scheme 1. Graphical representation of the principle involved in the homogeneous FRET assay.
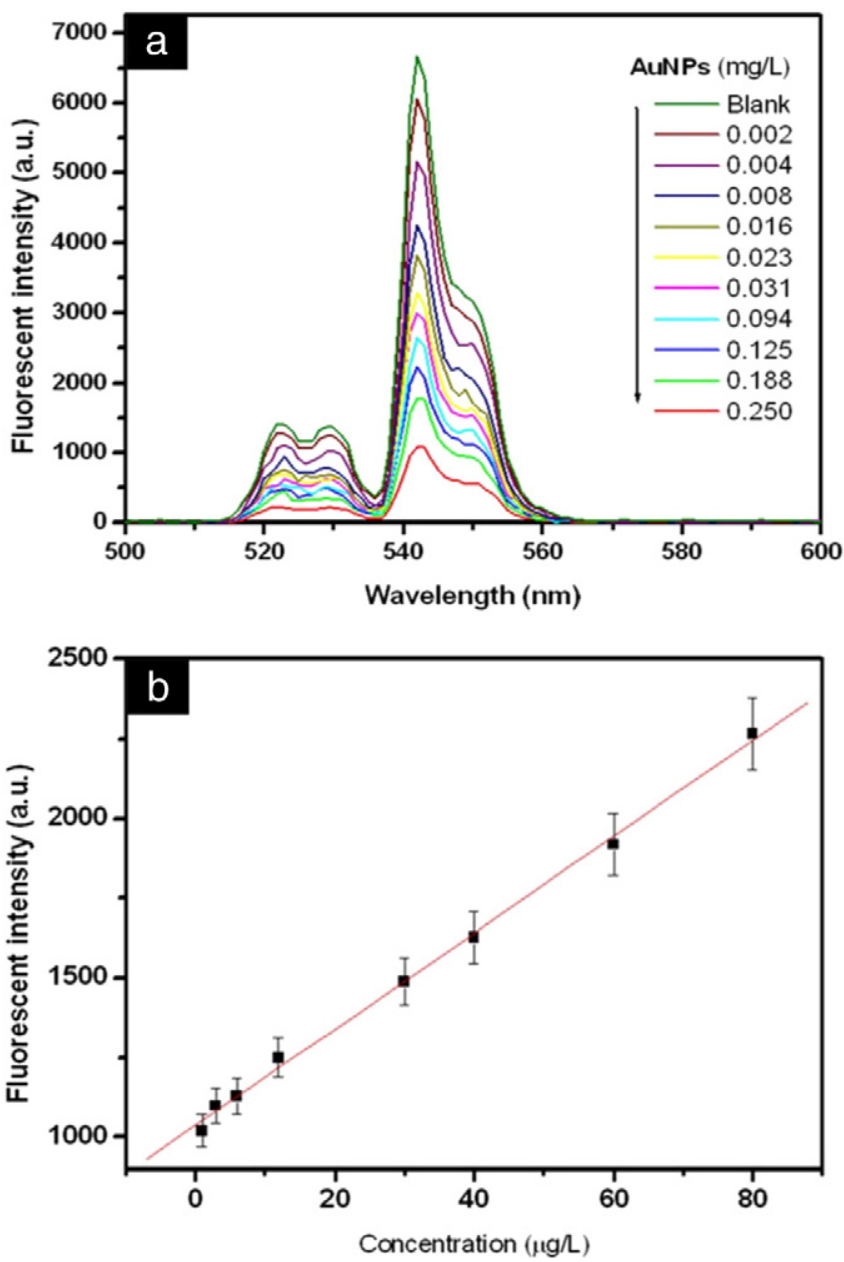

Fig. 4. (a) Fluorescence intensity of FRET system at various concentrations (0.002-0.250 mg/L) of antigen-conjugated AuNPs. This fluorescence quenching represents a donor action in FRET. (b) Typical standard calibration curve for enrofloxacin (ENR) by FRET under the optimized conditions.

obtained by present method are the same order with those of other methods for the detection of FQs (see Table 1). Therefore, it can be deemed as a good biosensor for on-line monitoring the FQs in environmental water samples.

\subsection{Tolerance evaluation studies}

The real environmental water samples were collected from various aquatic resources, such as tap, pond, and river water, which potentially possess various matrix effects. Various environmentally relevant parameters in aquatic system have to be considered such as salinity, water hardness, varied $\mathrm{pH}$ and heavy metals, as these could influence the specific immunoreactions or result in coagulation of NPs and thus, cause a negative impact on the FRET performance. Hence, the evaluation of the tolerance of the proposed method becomes vital in variation to these parameters.

Table 1

The LOD comparison with other methods.

\begin{tabular}{llll}
\hline Method & LOD/Linear range & Remark & Ref. \\
\hline FRET & $0.2 / 1-80\left(\mathrm{ng} \mathrm{mL}^{-1}\right)$ & One step- fast & This work \\
HPLC-RRS & $0.12 / 0.18-19.2\left(\mu \mathrm{mL}^{-1}\right)$ & Sophisticate & {$[61]$} \\
MIP-CE & $1.6 / 5-200\left(\mathrm{ng} \mathrm{mL}^{-1}\right)$ & More than one step & {$[62]$} \\
Colorimetric & $16 \mathrm{mg} \mathrm{mL}^{-1}$ & Slow process & {$[63]$} \\
\hline
\end{tabular}


Considering the case or real samples, where the $\mathrm{pH}$ is found to be in the range of $\mathrm{pH}$ 6.0-9.0, the established FRET assay has a good tolerance, as shown in Fig. S5a (ESI). This may be correlated to the high concentration of buffer used in the study. The effects of salinity were evaluated using $\mathrm{KCl}$ and $\mathrm{NaCl}$ as model salts. Fig. S5b (ESI) indicates that the method has high tolerance to both $\mathrm{K}^{+}$and $\mathrm{Na}^{+}$ions $(0-10 \%, \mathrm{w} / \mathrm{v})$. However, a relatively poor tolerance was observed after the introduction of $\mathrm{Ca}^{2+}$ and $\mathrm{Mg}^{2+}$ ions to the water samples. When the concentration of $\mathrm{Ca}^{2+}$ and $\mathrm{Mg}^{2+}$ exceeded $1.25 \%(\mathrm{w} / \mathrm{v})$, coagulation occurred in the system, and the interference cannot be eliminated by the addition of the complexing reagent (EDTA and oxalate, shown in Fig. S5c and d (ESI)). This can be ascribed to the aggregation of AuNPs [58]. By using EDTA for the removal of $\mathrm{Ca}^{2+}$ and $\mathrm{Mg}^{2+}$, there occurred the formation of new complexes at higher concentration of $\mathrm{Ca}^{2+}$ and $\mathrm{Mg}^{2+}$ and thus led to the change in color, as shown in Fig. S5c and S5d (ESI). Owing to low amounts of $\mathrm{Ca}^{2+}$ and $\mathrm{Mg}^{2+}$ present in surface water $(<1 \%, w / v)$, their effect on the FQs determination is negligible.

The effect of heavy metals was considered to cause the denaturation of the antibodies and antigens, and then subsequently lead to the disappearance of FRET. The following ions, namely $\mathrm{Cu}^{2+}, \mathrm{Hg}^{2+}, \mathrm{Pb}^{2+}$, and $\mathrm{Cr}^{2+}$, were chosen as potential interferes. Our results (data not shown) demonstrated that no obvious variations in the signal were noted after the addition of the heavy metal ions to the water samples $(0-1 \mathrm{mg} / \mathrm{L})$. These results are in agreement with our previous report [20].

\subsection{Accuracy verification}

The accuracy and precision of the proposed method were evaluated using different sources of water samples containing $2 \mu \mathrm{g} / \mathrm{L}$ for each one of ENR, CIP and NOR (three typical FQs). As shown in Table S2 (ESI), the intra-assay coefficient of variation (CV) values were 4.7-9.7\%, and the recoveries were within $73.5-114.5 \%$ (normalized value according to the cross-reactivity of Mab). The higher recovery values might have been originated from the calibration. The proposed method relies on calibration with suitable standards in solvent. In the case of real samples, the matrix effect is usually corrected by performing matrixmatched standards calibration or isotope dilution. Unfortunately, these techniques are found to be difficult in application to real time environmental analysis because of the higher variability in samples from different origin $[59,60]$. Nevertheless, the obtained recoveries were quite satisfactory and made a strong implication of the proposed approach to real sample analysis [2].

\section{Conclusions}

The current study demonstrates the multi-facets of the synthesized $\beta-N_{2 L u F}$ :Yb,Er,Gd UCPs with near hexagonal shapes, narrow size distribution, good mono-dispersibility, and high efficiency. The direct surface modification using PAA-based ligand exchange strategy showed an excellent dispersibility in water after the covalent linkage of the - $\mathrm{COOH}$ group. The FRET approach had been developed using UCPs as donors and AuNPs as acceptors and successfully applied for the detection of trace amounts of FQs in environmental waters. The proposed homogeneous method was accurate with a high tolerance limit against various potential interferes. It involves a simple one step process involving only filtration and without any sample pretreatment, separation, or washing steps. Therefore, the immense potency of the method using high cross-reactivity FQs Mab, toward the on-line monitoring of total amount of a class of compounds in environmental waters can be well established.

\section{Acknowledgments}

This work was supported by the National Natural Science Foundation of China (21107036), the Ph.D. Programs Foundation of the
Ministry of Education of China (20113227120005), the Regional University Research Program (NRF 2014-008793) through the National Research Foundation of Korea (NRF).

\section{Appendix A. Supplementary data}

Supplementary data to this article can be found online at http://dx. doi.org/10.1016/j.microc.2015.08.024.

\section{References}

[1] M. Seifrtova, L. Novakova, C. Lino, A. Pena, P. Solich, An overview of analytical methodologies for the determination of antibiotics in environmental waters, Anal. Chim. Acta 649 (2009) 158-179.

[2] V. Andreu, C. Blasco, Y. Pico, Analytical strategies to determine quinolone residues in food and the environment, TrAC, Trends Anal. Chem. 26 (2007) 534-556.

[3] L.M. Cao, D.X. Kong, J.X. Sui, T. Jiang, Z.Y. Li, L. Ma, H. Lin, Broad-specific antibodies for a generic immunoassay of quinolone: development of a molecular model for selection of haptens based on molecular field-overlapping, Anal. Chem. 81 (2009) 3246-3251.

[4] A.V. Herrera-Herrera, J. Hernandez-Borges, M.A. Rodriguez-Delgado, M. Herrero, A Cifuentes, Determination of quinolone residues in infant and young children powdered milk combining solid-phase extraction and ultra-performance liquid chromatography-tandem mass spectrometry, J. Chromatogr. A 1218 (2011) 7608-7614.

[5] A.M. Garcia-Campana, L. Gamiz-Gracia, F.J. Lara, M.D. Iruela, C. Cruces-Blanco, Applications of capillary electrophoresis to the determination of antibiotics in food and environmental samples, Anal. Bioanal. Chem. 395 (2009) 967-986.

[6] N. Dorival-Garcia, A. Zafra-Gomez, S. Cantarero, A. Navalon, J.L. Vilchez, Simultaneous determination of 13 quinolone antibiotic derivatives in wastewater samples using solid-phase extraction and ultra performance liquid chromatographytandem mass spectrometry, Microchem. J. 106 (2013) 323-333.

[7] E.M. Golet, A.C. Alder, W. Giger, Environmental exposure and risk assessment of fluoroquinolone antibacterial agents in wastewater and river water of the Glatt Valley Watershed, Switzerland, Environ. Sci. Technol. 36 (2002) 3645-3651.

[8] Yiruhan, Q.J. Wang, C.H. Mo, Y.W. Li, P. Gao, Y.P. Tai, Y. Zhang, Z.L. Ruan, J.W. Xu, Determination of four fluoroquinolone antibiotics in tap water in Guangzhou and Macao, Environ. Pollut. 158 (2010) 2350-2358.

[9] X.A. Ton, V. Acha, K. Haupt, T.S.B. Bernadette, Direct fluorimetric sensing of UV-excited analytes in biological and environmental samples using molecularly imprinted polymer nanoparticles and fluorescence polarization, Biosens. Bioelectron. 36 (2012) 22-28.

[10] K.H. Wammer, A.R. Korte, R.A. Lundeen, J.E. Sundberg, K. McNeill, W.A. Arnold, Direct photochemistry of three fluoroquinolone antibacterials: norfloxacin, ofloxacin, and enrofloxacin, Water Res. 47 (2013) 439-448.

[11] R.H. Lindberg, K. Bjorklund, P. Rendahl, M.I. Johansson, M. Tysklind, B.A.V. Andersson, Environmental risk assessment of antibiotics in the Swedish environment with emphasis on sewage treatment plants, Water Res. 41 (2007) 613-619.

[12] S.R. Raz, M. Bremer, W. Haasnoot, W. Norde, Label-free and multiplex detection of antibiotic residues in milk using imaging surface plasmon resonance-based immunosensor, Anal. Chem. 81 (2009) 7743-7749.

[13] G. Carlsson, S. Orn, D.G.J. Larsson, Effluent from bulk drug production is toxic to aquatic vertebrates, Environ. Toxicol. Chem. 28 (2009) 2656-2662.

[14] J.E. Moore, J.R. Rao, P.J.A. Moore, B.C. Millar, C.E. Goldsmith, A. Loughrey, P.J. Rooney Determination of total antibiotic resistance in waterborne bacteria in rivers and streams in Northern Ireland: can antibiotic-resistant bacteria be an indicator of ecological change? Aquat. Ecol. 44 (2010) 349-358.

[15] H. Yan, F. Qiao, K.H. Row, Molecularly imprinted-matrix solid-phase dispersion for selective extraction of five fluoroquinolones in eggs and tissue, Anal. Chem. 79 (2007) 8242-8248.

[16] M. Franek, K. Hruska, Antibody based methods for environmental and food analysis: a review, Vet. Med. 50 (2005) 1-10.

[17] M.A. Gonzalez-Martinez, R. Puchades, A. Maquieira, On-line immunoanalysis for environmental pollutants: from batch assays to automated sensors, TrAC, Trends Anal. Chem. 18 (1999) 204-218.

[18] J.L. Yuan, K. Matsumoto, H. Kimura, A new tetradentate beta-diketonateEuropium chelate that can be covalently bound to proteins for time-resolved fluoroimmunoasaay, Anal. Chem. 70 (1998) 596-601.

[19] Z.H. Wang, Y.Zhu, S.Y. Ding, F.Y. He, R.C. Beier, J.C. Li, H.Y. Jiang, C.W. Feng, Y.P. Wan, S.X. Zhang, Z.P. Kai, X.L. Yang, J.Z. Shen, Development of a monoclonal antibodybased broad-specificity ELISA for fluoroquinolone antibiotics in foods and molecular modeling studies of cross-reactive compounds, Anal. Chem. 79 (2007) 4471-4483.

[20] Z. Zhang, J.-f. Liu, B. Shao, G.-b. Jiang, Time-resolved fluoroimmunoassay as an advantageous approach for highly efficient determination of sulfonamides in environmental waters, Environ. Sci. Technol. 44 (2009) 1030-1035.

[21] M. He, Z. Liu, Paper-based microfluidic device with upconversion fluorescence assay Anal. Chem. 85 (2013) 11691-11694

[22] D. GeiSsler, S. Stufler, H.-G. Lohmannsroben, N. Hildebrandt, Six-color time-resolved forster resonance energy transfer for ultrasensitive multiplexed biosensing, J. Am. Chem. Soc. 135 (2013) 1102-1109.

[23] S. Wu, N. Duan, X. Ma, Y. Xia, H. Wang, Z. Wang, Q. Zhang, Multiplexed fluorescence resonance energy transfer aptasensor between upconversion nanoparticles and 
graphene oxide for the simultaneous determination of mycotoxins, Anal. Chem. 84 (2012) 6263-6270

[24] P. Zhang, S. Rogelj, K. Nguyen, D. Wheeler, Design of a highly sensitive and specific nucleotide sensor based on photon upconverting particles, J. Am. Chem. Soc. 128 (2006) 12410-12411.

[25] Y. Tang, Y. Liu, A. Cao, Strategy for sensor based on fluorescence emission red shift of conjugated polymers: applications in $\mathrm{pH}$ response and enzyme activity detection, Anal. Chem. 85 (2012) 825-830.

[26] Y.H. Wang, P. Shen, C.Y. Li, Y.Y. Wang, Z.H. Liu, Upconversion fluorescence resonance energy transfer based biosensor for ultrasensitive detection of matrix metalloproteinase-2 in blood, Anal. Chem. 84 (2012) 1466-1473.

[27] Y. Wang, Z. Wu, Z. Liu, Upconversion fluorescence resonance energy transfer biosensor with aromatic polymer nanospheres as the lable-free energy acceptor, Anal. Chem. 85 (2013) 258-264.

[28] J.Q. Gu, L.D. Sun, Z.G. Yan, C.H. Yan, Luminescence resonance energy transfer sensors based on the assemblies of oppositely charged lanthanide/gold nanoparticles in aqueous solution, Chem. Asian. J. 3 (2008) 1857-1864.

[29] M. Wang, W. Hou, C.C. Mi, W.X. Wang, Z.R. Xu, H.H. Teng, C.B. Mao, S.K. Xu, Immunoassay of goat antihuman immunoglobulin $\mathrm{G}$ antibody based on luminescence resonance energy transfer between near-infrared responsive $\mathrm{NaYF}_{4}: \mathrm{Yb}, \mathrm{Er}$ upconversion fluorescent nanoparticles and gold nanoparticles, Anal. Chem. 81 (2009) 8783-8789.

[30] A. Periasamy, Fluorescence resonance energy transfer microscopy: a mini review, J. Biomed. Opt. 6 (2001) 287-291.

[31] L.E. Morrison, Time-resolved detection of energy transfer: theory and application to immunoassays, Anal. Biochem. 174 (1988) 101-120.

[32] K. Kuningas, T. Ukonaho, H. Pakkila, T. Rantanen, J. Rosenberg, T. Lovgren, T. Soukka, Upconversion fluorescence resonance energy transfer in a homogeneous immunoassay for estradiol, Anal. Chem. 78 (2006) 4690-4696.

[33] J. Zhou, Z. Liu, F. Li, Upconversion nanophosphors for small-animal imaging, Chem. Soc. Rev. 41 (2012) 1323-1349.

[34] F. Wang, X. Liu, Recent advances in the chemistry of lanthanide-doped upconversion nanocrystals, Chem. Soc. Rev. 38 (2009) 976-989.

[35] M. Wang, C.C. Mi, W.X. Wang, C.H. Liu, Y.F. Wu, Z.R. Xu, C.B. Mao, S.K. Xu, Immunolabeling and NIR-excited fluorescent imaging of HeLa cells by using $\mathrm{NaYF}_{4}: \mathrm{Yb}$, Er upconversion nanoparticles, ACS Nano 3 (2009) 1580-1586.

[36] Z.G. Chen, H.L. Chen, H. Hu, M.X. Yu, F.Y. Li, Q. Zhang, Z.G. Zhou, T. Yi, C.H. Huang, Versatile synthesis strategy for carboxylic acid-functionalized upconverting nanophosphors as biological labels, J. Am. Chem. Soc. 130 (2008) 3023-3029.

[37] B. Dubertret, P. Skourides, D.J. Norris, V. Noireaux, A.H. Brivanlou, A. Libchaber, In vivo imaging of quantum dots encapsulated in phospholipid micelles, Science 298 (2002) 1759-1762

[38] I.L. Medintz, H.T. Uyeda, E.R. Goldman, H. Mattoussi, Quantum dot bioconjugates for imaging, labelling and sensing, Nat. Mater. 4 (2005) 435-446.

[39] Q. Liu, Y. Sun, T. Yang, W. Feng, C. Li, F. Li, Sub-10 nm hexagonal lanthanide-doped $\mathrm{NaLuF}_{4}$ upconversion nanocrystals for sensitive bioimaging in vivo, J. Am. Chem. Soc. 133 (2011) 17122-17125.

[40] T.A. Taton, C.A. Mirkin, R.L. Letsinger, Scanometric DNA array detection with nanoparticle probes, Science 289 (2000) 1757-1760.

[41] Z. Zhang, J.-F. Liu, T.-T. Feng, Y. Yao, L.-H. Gao, G.-B. Jiang Time-resolved fluoroimmunoassay as an advantageous analytical method for assessing the total concentration and environmental risk of fluoroquinolones in surface waters, Environ. Sci. Technol. 47 (2013) 454-462.

[42] C. Liu, H. Wang, X. Li, D. Chen, Monodisperse, size-tunable and highly efficient betaNaYF4:Yb, $\operatorname{Er}(\mathrm{Tm})$ up-conversion luminescent nanospheres: controllable synthesis and their surface modifications, J. Mater. Chem. 19 (2009) 3546-3553.

[43] T. Yang, Y. Sun, Q. Liu, W. Feng, P. Yang, F. Li, Cubic sub-20 nm NaLuF4-based upconversion nanophosphors for high-contrast bioimaging in different animal species, Biomaterials 33 (2012) 3733-3742.

[44] F. Wang, Y. Han, C.S. Lim, Y.H. Lu, J. Wang, J. Xu, H.Y. Chen, C. Zhang, M.H. Hong, X.G. Liu, Simultaneous phase and size control of upconversion nanocrystals through lanthanide doping, Nature 463 (2010) 1061-1065.
[45] X.H. Ji, X.N. Song, J. Li, Y.B. Bai, W.S. Yang, X.G. Peng, Size control of gold nanocrystals in citrate reduction: the third role of citrate, J. Am. Chem. Soc. 129 (2007) 13939-13948.

[46] L.A. Lyon, M.D. Musick, M.J. Natan, Colloidal Au-enhanced surface plasmon resonance immunosensing, Anal. Chem. 70 (1998) 5177-5183.

[47] G.A. Sotiriou, D. Franco, D. Poulikakos, A. Ferrari, Optically stable biocompatible flame-made $\mathrm{SiO}_{2}$-coated $\mathrm{Y}_{2} \mathrm{O}_{3}: \mathrm{Tb}_{3}+$ nanophosphors for cell imaging, ACS Nano 6 (2012) 3888-3897.

[48] C. Li, J. Yang, P. Yang, X. Zhang, H. Lian, J. Lin, Two-dimensional $\beta-\mathrm{NaLuF}_{4}$ hexagonal microplates, Cryst. Growth Des. 8 (2008) 923-929.

[49] F. Zhang, Y. Wan, T. Yu, F. Zhang, Y. Shi, S. Xie, Y. Li, L. Xu, B. Tu, D. Zhao, Uniform nanostructured arrays of sodium rare-earth fluorides for highly efficient multicolor upconversion luminescence, Angew. Chem. 119 (2007) 8122-8125.

[50] Y. Cui, S. Zhao, Z. Liang, M. Han, Z. Xu, Optimized upconversion emission of NaLuF4: Er, Yb nanocrystals codoped with Gd3 + ions and its mechanism, J. Alloys Compd. 593 (2014) 30-33.

[51] T. Zhang, J. Ge, Y. Hu, Y. Yin, A general approach for transferring hydrophobic nanocrystals into water, Nano Lett. 7 (2007) 3203-3207.

[52] B. Liu, H. Tan, Y. Chen, Upconversion nanoparticle-based fluorescence resonance energy transfer assay for Cr(III) ions in urine, Anal. Chim. Acta 761 (2013) 178-185.

[53] T. Cao, Y. Yang, Y. Gao, J. Zhou, Z. Li, F. Li, High-quality water-soluble and surfacefunctionalized upconversion nanocrystals as luminescent probes for bioimaging, Biomaterials 32 (2011) 2959-2968.

[54] M. Wang, C. Mi, Y. Zhang, J. Liu, F. Li, C. Mao, S. Xu, NIR-responsive silica-coated NaYbF4:Er/Tm/Ho upconversion fluorescent nanoparticles with tunable emission colors and their applications in immunolabeling and fluorescent imaging of cancer cells, J. Phys. Chem. C 113 (2009) 19021-19027.

[55] S. Wu, N. Duan, C. Zhu, X. Ma, M. Wang, Z. Wang, Magnetic nanobead-based immunoassay for the simultaneous detection of aflatoxin B1 and ochratoxin A using upconversion nanoparticles as multicolor labels, Biosens. Bioelectron. 30 (2011) 35-42.

[56] C. Liu, Z. Wang, X. Wang, Z. Li, Surface modification of hydrophobic NaYF4:Yb, Er upconversion nanophosphors and their applications for immunoassay, Sci. China Chem. 54 (2011) 1292-1297.

[57] L.Y. Wang, R.X. Yan, Z.Y. Hao, L. Wang, J.H. Zeng, H. Bao, X. Wang, Q. Peng, Y.D. Li, Fluorescence resonant energy transfer biosensor based on upconversionluminescent nanoparticles, Angew. Chem. Int. Ed. 44 (2005) 6054-6057.

[58] J. Zhang, Y. Wang, X. Xu, X. Yang, Specifically colorimetric recognition of calcium, strontium, and barium ions using 2-mercaptosuccinic acid-functionalized gold nanoparticles and its use in reliable detection of calcium ion in water, Analyst 136 (2011) 3865-3868.

[59] O.J. Pozo, C. Guerrero, J.V. Sancho, M. Ibáñez, E. Pitarch, E. Hogendoorn, F. Hernández, Efficient approach for the reliable quantification and confirmation of antibiotics in water using on-line solid-phase extraction liquid chromatography/tandem mass spectrometry, J. Chromatogr. A 1103 (2006) 83-93.

[60] M. Ferdig, A. Kaleta, T.D. Thanh Vo, W. Buchberger, Improved capillary electrophoretic separation of nine (fluoro)quinolones with fluorescence detection for biological and environmental samples, J. Chromatogr. A 1047 (2004) 305-311.

[61] M. Zhou, J. Peng, R. He, Y. He, J. Zhang, A. Li, High performance liquid chromatography coupled with resonance Rayleigh scattering for the detection of three fluoroquinolones and mechanism study, Spectrochim. Acta A Mol. Biomol. Spectrosc. 136 (Part B) (2015) 1181-1187.

[62] M.-M. Zheng, R. Gong, X. Zhao, Y.-Q. Feng, Selective sample pretreatment by molecularly imprinted polymer monolith for the analysis of fluoroquinolones from milk samples, J. Chromatogr. A 1217 (2010) 2075-2081.

[63] T.I.B. Silva, F.T.C. Moreira, L.A.A.N.A. Truta, M.G.F. Sales, Novel optical PVC probes for on-site detection/determination of fluoroquinolones in a solid/liquid interface: application to the determination of norfloxacin in aquaculture water, Biosens. Bioelectron. 36 (2012) 199-206. 